\title{
Genetic Control of the Eighth Component of Complement
}

\author{
Donald Raum, M. Anne Spence, Diane Balavitch, Susan Tideman, A. Donald \\ Merritt, R. Thomas Taggart, Bruce H. Petersen, Noorbibi K. Day, and \\ Chester A. AlPER, Center for Blood Research and the Department of Medicine, \\ Children's Hospital Medical Center, Boston, Massachusetts 02115; Departments \\ of Psychiatry and Biomathematics and the Mental Retardation Research Center, \\ University of California at Los Angeles, School of Medicine, Los Angeles, \\ California 90024; the Lilly Laboratory for Clinical Research and Indiana \\ University School of Medicine, Indianapolis, Indiana 46202; and Sloan-Kettering \\ Institute for Cancer Research, New York 10021
}

\begin{abstract}
A B S TRACT Using isoelectric focusing in polyacrylamide gel and a hemolytic assay for development of patterns, extensive structural polymorphism in human $\mathrm{C} 8$ has been delineated. Two alleles, $\mathrm{C} 8^{\mathrm{A}}$ and $C 8^{\mathrm{B}}$, have been identified in orientals, with gene frequencies of 0.655 and 0.345 . In blacks, what appears to be a third common allele was found, so that frequencies were $0.692,0.259$, and 0.049 for $C 8^{\mathrm{A}}, \mathrm{C} 8^{\mathrm{B}}$, and $\mathrm{C} 8^{\mathrm{A} 1}$. In whites, $\mathrm{C} 8^{\mathrm{A} 1}$ was rare with a frequency of 0.003 , and frequencies for $\mathrm{C}^{\mathrm{A}}$ and $\mathrm{C} 8^{\mathrm{B}}$ were 0.649 and 0.349. Inheritance was autosomal codominant in family studies and the distribution of types in random unrelated populations fit the Hardy-Weinberg equilibrium in all groups.

C8 allotypes have been determined for two previously studied familes, each with a homozygous C8-deficient propositus. This study suggests that $\mathrm{C} 8$ deficiency is a silent or null allele of the C8 structural locus, and that half normal levels of $\mathrm{C} 8$ cannot be used as a single criterion for the establishment of heterozygous C8 deficiency. C8 allotypes, as well as 18 other autosomal markers, were also determined for 24 familes. The C8 structural locus is not closely linked to these markers, including the human histocompatibility loci complex.
\end{abstract}

\section{INTRODUCTION}

Extensive genetic polymorphism has been described in a number of complement proteins, including $\mathrm{C}^{1}$

\footnotetext{
Received for publication 29 January 1979 and in revised form 14 May 1979.

${ }^{1}$ Abbreviations used in this paper: Bf, properdin factor B; C3, third component of complement; HLA, human histocompatibility loci; C6, sixth component of complement; C4, fourth component of complement; $\mathrm{C} 2$, second component of complement; C7, seventh component of complement; C8, eighth component of complement; C5, fifth component of complement; C9, ninth component of complement.
}

$(1,2)$, C6 (3), and properdin factor B (4). There appears also to be extensive polymorphism in $\mathrm{C} 4(5-7)$, but there is disagreement with respect to the number and nature of alleles, the number of genetic loci, and the ability to detect heterozygotes. Less extensive inherited structural variation occurs in C2 $(8,9), C 7(9,10)$, and properdin factor $D(9)$.

Inherited deficiency states for almost all complement proteins, including inhibitors, have been described (11), including deficiency of C8 in three families (12-14). The availability of C8-deficient serum from one affected individual (12) made possible the present study which is concerned with genetic structural polymorphism in human C8.

Genetic polymorphism of human complement proteins has been used to explore the linkage relationships of the corresponding genes and to study the inheritance of deficiency states. Study of the polymorphism of properdin factor $\mathrm{B}$ ( $\mathrm{Bf}[4,15])$ led to discovery of linkage of the loci for $\mathrm{Bf}$ and human histocompatibility loci (HLA [2]).

Studies of C3 polymorphism $(1,2)$ and C3 deficiency established inherited C3 deficiency to be a phenotypic expression of an allele at the C3 structural locus (16). The locus for inherited C2 deficiency was also noted to be closely linked to the HLA region $(17,18)$. Subsequent studies of $\mathrm{C} 2$ polymorphism have confirmed this $(8-10$, $19)$ and that $C 2$ deficiency is an allele of the $C 2$ structural locus (20). Narrow ranges in the normal levels of C2 often make possible identification of heterozygous carriers of C2 deficiency from serum C2 concentrations in family studies (21). Detection of C6-deficient heterozygotes, despite a somewhat wider range of normal concentration is also possible and has been aided by the addition of studies of C6 polymorphism (22). These studies also confirmed that C6 deficiency is an allele at the C6 structural locus. 
The intimate association of $\mathrm{C} 2$ and $\mathrm{Bf}$ with the HLA complex and each other (23) has raised the question of the linkage of other human complement components to each other and HLA (24). Concordant inheritance of polymorphism of C6 and C7 and of a combined defect of $\mathrm{C} 6$ and $\mathrm{C7}$ in families suggests the linkage of C6 and C7 $(9,25)$. Studies of the polymorphism of C4 and the C4-deficiency state have led to the conclusion that C4 is linked to HLA $(5-7,26,27)$ and corresponding studies of the relevant proteins that $\mathrm{C} 3$ (28), C5 $(29,30)$, C6 $(31,32)$, and C7 $(33,34,10)$ are not closely linked to HLA. Two studies of the relationship of C8 deficiency to HLA in large families have been described $(35,13)$. In the first study (35), it was concluded that $\mathrm{C} 8$ was closely linked to HLA. In the second family (13), C8 deficiency was associated with several different HLA types in three homozygous deficient subjects, and it was concluded that C8 was not closely linked to HLA. A similar conclusion was reached from study of a small, third family (14). In this family, children of heterozygous C8-deficient parents are described in which one presumed HLA-C8 deficiency crossover must have occurred on the hypothesis of linkage. The delineation of C8 polymorphism has made it possible to restudy this question with less difficulty in the ascertainment of heterozygous deficient individuals and to demonstrate that $\mathrm{C} 8$ deficiency or $\mathrm{C}^{-}$ is an allele of the C8 structural locus. The study of families with C8 structural markers, but no serum concentration abnormality, has facilitated linkage studies with other genetic markers and is reported here.

\section{METHODS}

Serum samples. Serum samples were obtained by centrifugation from whole blood allowed to clot at room temperature for $\cong 30 \mathrm{~min}$ and at $4^{\circ} \mathrm{C}$ for $1 \mathrm{~h}$. Serum samples were stored at $-80^{\circ} \mathrm{C}$ for periods up to $10 \mathrm{yr}$ before thawing and analysis. Serum from an individual with C3 deficiency (36) contained $\cong 20 \mathrm{ng} / \mathrm{ml}$ of C3 (37). Serum from a homozygous C5-deficient person $(29,30)$ was kindly supplied by Dr. John Leddy, University of Rochester, Rochester, N. Y.; from a homozygous C6-deficient individual (31) by Dr. Arthur Rabson, South African Institute for Medical Research, Johannesburg, South Africa; from a homozygous C7-deficient person by Dr. Harry Feldman, State University of New York Upstate Medical Center, Syracuse, N. Y.

Families studied were those previously described (38-40). Lod scores were calculated by the LIPED Program (41) for the following routinely determined genetic markers: $\mathrm{Bf}, \mathrm{C} 2$, C3, C6, Gc, haptoglobin, glyoxalase I, Gm, HLA, and $A_{1}, A, H$, B, D, C, E, c, e, C ${ }^{\mathrm{w}}, \mathrm{P}, \mathrm{K}, \mathrm{k}, \mathrm{Kp}^{\mathrm{a}}, \mathrm{Kp}^{\mathrm{b}}, \mathrm{Le}^{\mathrm{a}}, \mathrm{Le}^{\mathrm{b}}, \mathrm{M}, \mathrm{N}, \mathrm{S}, \mathrm{s}, \mathrm{Lu}^{\mathrm{a}}$, $\mathrm{Lu}^{\mathrm{b}}, \mathrm{Jk}^{\mathrm{a}}$, and $\mathrm{Fy}^{\mathrm{a}}$. HLA typing was done by the microdroplet lymphocyte cytotoxicity test (42). The following routinely determined markers were not informative for linkage in any of the 24 families: Inv, Tf, Or, $\mathrm{Cp}, \mathrm{Pi}, \mathrm{Js}^{\mathrm{a}}, \mathrm{V}^{\mathrm{w}}, \mathrm{He}, \mathrm{Mg}, \mathrm{Wr}^{\mathrm{a}}$, Vel, $\mathrm{Yt}^{\mathrm{a}}, \mathrm{I}$, and $\mathrm{Xg}^{\mathrm{a}}$.

Isoelectric focusing in thin-layer polyacrylamide gel. The method of Awdeh et al. (43), modified as described previously (3), was used. Ampholytes (LKB Instruments, Inc., Rockville, Md., and Bio-Rad Laboratories, Richmond, Calif.) in a range of pH 5-10 at a final concentration of $2 \%$ (three parts Bio-Rad pH 5-7, three parts Bio-Rad pH 7-9 and one part LKB pH 3.5-10) were incorporated into $5 \%$ acrylamide gels with $0.2 \mathrm{M}$ taurine. The gels were polymerized with riboflavin and light. Approximately 5 - $\mu$ l samples were applied by moistening small rectangles of Whatman No. 1 filter paper and placing them on the gel surface near the anode. Isoelectric focusing was done for $24 \mathrm{~h}$ at $450 \mathrm{~V}$.

Developing gel. When isoelectric focusing was complete ( $\cong 20 \mathrm{~h}$ ), a $1-\mathrm{mm}$ thick layer of $0.6 \%$ agarose (Marine Colloids, Inc., Rockland, Maine) in isotonic Veronal-buffered saline at pH 7.4 containing $0.1 \%$ gelatin, $1 \mathrm{mM} \mathrm{Mg}^{++}$and $0.15 \mathrm{mM}$ $\mathrm{Ca}^{++}, 0.8 \%$ sheep erythrocytes sensitized with rabbit antibody, and $3 \%$ homozygous C8-deficient human serum (12) was poured over the acrylamide gel. After a 1-2-h incubation at $37^{\circ} \mathrm{C}$, bands of hemolysis developed optimally. For preservation of patterns, the agarose gel was separated from the acrylamide gel and then immersed in $2 \%$ glutaraldehyde solution in phosphate-buffered isotonic saline for $30 \mathrm{~min}$ at $4^{\circ} \mathrm{C}$. The agarose gels were than soaked with distilled water overnight and allowed to dry on glass plates.

\section{RESULTS}

Bands of lysis developed regularly in the $\mathrm{pH}$ range 6.2-6.5. Almost all sera also produced zones and (or) bands of lysis more cathodally. Both zones appeared to be $\mathrm{C} 8$-induced because $\mathrm{C} 8$-deficient serum produced neither, and C3-, C5-, C6-, and C7-deficient human sera produced both. Because band formation occurred irregularly in the cathodal area, and because there appeared to be no simple correspondence between lysis bands in this area and the distinct patterns in the more anodal area, the cathodal zones and bands were ignored in subsequent analysis.

In orientals, three patterns of lysis were observed. Patterns from presumed homozygotes consisted of two (or sometimes three) bands of decreasing intensity from cathode to anode. In occasional patterns from homozygotes, the two most basic bands were nearly equal in intensity. Proceeding from cathode to anode, the first (major) band of C8A approximately coincided with the second (minor) band of C8B. In C8AB sera there were three easily visible bands, the middle one of which was most prominent and consisted of the superimposed major cathodal band of C8A and minor anodal band of C8B. On some plates, the major band of $\mathrm{C} 8 \mathrm{~A}$ was slightly more anodal than the minor band of C8B and in such cases C8AB consisted of four bands. In some sera from blacks and a single white, a variant more acidic than C8A was found. This was designated C8Al and had the appearance of C8A and C8B except that its major cathodal band roughly corresponded in position to the minor anodal band of C8A. These findings are illustrated in Fig. 1.

The genetic model for $\mathrm{C} 8$ polymorphism postulates two alleles in orientals and three in blacks and whites and assumes autosomal codominant Mendelian inheritance. This was tested in families, as shown in Table I. It can be seen that this mode of inheritance was borne 


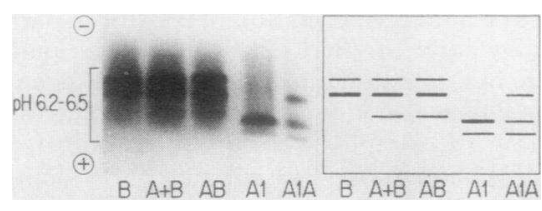

FIGURE 1 Isoelectric focusing of human serum samples followed by development of bands of hemolysis induced by C8. C8 types are given below the appropriate patterns.

out by the family studies. There was male-to-male transmission of the proposed genes and some males were heterozygous, supporting the autosomal localization of the C8 structural gene locus.

Gene frequencies were tested in populations of unrelated individuals and are given in Table II. Further support for the autosomal codominant inheritance of C8 structural genes is provided by the observation that the distribution of types among individuals in the three major races of man fits those predicted by the HardyWeinberg equilibrium (Table III). By $\chi^{2}$ analysis, there were no significant differences between observed and expected incidences in any of the races.

26 mother-cord pairs demonstrate fetal synthesis and failure of transplacental passage. These results are given in Table IV.

Fig. 2 shows family $O-Q$ (13). In a previous paper, individuals 146,69 , and 150 were identified as C8deficient, whereas individuals $145,151,139,67,6 \mathbf{x}$, and $7 x$ were identified as heterozygous deficient. Neither of the individuals 99 or 98 who were obligate heterozygous deficient individuals were so defined by immunochemical or hemolytic determinations. Individuals 141 and 143 were identified as having C8 functional levels $<1$ SD below normal value, and individual 66 had a normal immunochemical level of C8 with low functional level. With regard to the C8 allotypes of this family, as expected, samples from 146, 150 , and 69 give no patterns. The remainder of the family have phenotype $A$ with the exception of the spouse and children of 139 . Individual 140 with normal levels of $\mathrm{C} 8$ is type $\mathrm{B}$, presumably genotypically $\mathrm{C}^{\mathrm{BB}}$.

TABLE I

C8 Types in Families

\begin{tabular}{|c|c|c|c|c|}
\hline \multirow{2}{*}{$\begin{array}{c}\text { Parental } \\
\text { types }\end{array}$} & \multirow[b]{2}{*}{ No. of families } & \multicolumn{3}{|c|}{ Offspring types* } \\
\hline & & $\mathbf{A A}$ & $\mathbf{A B}$ & BB \\
\hline $\mathbf{A A} \times \mathbf{A A}$ & 3 & $14(14)$ & 0 & $\mathbf{0}$ \\
\hline $\mathbf{A A} \times \mathbf{B B}$ & 4 & 0 & $14(14)$ & 0 \\
\hline $\mathbf{A A} \times \mathbf{A B}$ & 10 & $17(16.5)$ & $16(16.5)$ & 0 \\
\hline $\mathbf{A B} \times \mathbf{B B}$ & 4 & 0 & $5(5)$ & $5(5)$ \\
\hline $\mathbf{A B} \times \mathbf{A B}$ & 6 & $5(4.75)$ & $9(9.5)$ & $5(4.75)$ \\
\hline
\end{tabular}

* Expected numbers are given in parentheses.
TABLE II

C8 Gene Frequencies among Random Unrelated Individuals

\begin{tabular}{lcccc}
\hline Population & No. tested & $\mathrm{C}^{\wedge}$ & $\mathrm{C}^{\mathrm{A}}$ & $\mathrm{C}^{\mathrm{A}}$ \\
\hline Black & & & & \\
$\quad$ Brazil & 34 & 0.662 & 0.309 & 0.029 \\
U.S.A. & 130 & 0.700 & 0.246 & 0.054 \\
Total & 164 & 0.692 & 0.259 & 0.049 \\
White & 165 & 0.649 & 0.348 & 0.003 \\
Oriental & 29 & 0.655 & 0.345 & - \\
\hline
\end{tabular}

Individual 139 is a presumed heterozygous deficient relative of 146,150 , and 69 with presumed genotype $\mathrm{C}^{\mathrm{A}-}$. Their children, 142,143 , and 144 have phenotypes $C 8 \mathrm{AB}$, and they have child 141 with phenotype $B$ consistent with the above hypothesis and presumably of genotype $\mathrm{C}^{\mathrm{B}-}$. It is concluded from study of this family that the data are consistent with the hypothesis that $\mathrm{C}^{-}$is an allele at the C8 structural locus. In this family, at least three individuals have been misidentified as noncarriers of the $\mathrm{C}^{-}$allele by immunochemical and functional assays.

Fig. 3 shows family $16178(12,35)$ in which the individual 0001 has been identified as homozygous C8deficient and the individuals 1041, 1000, 0123, 0124, $9000,9001,0102,1001$, and 1005 were identified as heterozygous C8-deficient by functional and immunochemical assay (12). Individuals 1000, 1001, 9000, 9001, and 9038 are obligate heterozygous C8-deficient individuals because they are the parents and children of 0001 . In a previous paper, $\mathrm{C}^{-}$was called C8B (12). This is not to be confused with the system of naming alleles used here in which C8B refers to a surface charge variant.

With regard to the $\mathrm{C} 8$ phenotypes of these individuals, the five obligate heterozygous deficient individuals are phenotypically homozygous; $1000 \mathrm{C} 8 \mathrm{Al}, 1001 \mathrm{C} 8 \mathrm{~A}$, $9000 \mathrm{C} 8 \mathrm{~B}, 90001 \mathrm{C} 8 \mathrm{~A}$, and $9038 \mathrm{C} 8 \mathrm{~A}$. However, two of the children of $1014 \mathrm{C} 8 \mathrm{~A} 1 \mathrm{~A}$ and $1000 \mathrm{C} 8 \mathrm{~A}$ are phenotypically heterozygous for C8, $0123 \mathrm{C} 8 \mathrm{AlA}$ and 0124 C8AlA, suggesting that they are not heterozygous C8-deficient as previously thought. The matings of $1001 \mathrm{C} 8 \mathrm{~A}$ with an untested husband and with $1002 \mathrm{C8A}$ are uninformative with regard to establishing or disproving heterozygous $\mathrm{C} 8$ deficiency in children 0101 C8A, 0102 C8A, 0100 C8A, 0103 C8A, and 0104 C8A. The mating of $1005 \mathrm{C} 8 \mathrm{~B}$ and $1006 \mathrm{C} 8 \mathrm{AB}$ is uninformative with regard to $\mathrm{C} 8$ deficiency in child $0112 \mathrm{C} 8 \mathrm{~B}$. However, these data are consistent with the hypothesis that $\mathrm{C8}^{-}$is a silent allele at the $\mathrm{C} 8$ structural locus. The mating of $1009 \mathrm{C} 8 \mathrm{~B}$ to an untested husband 1010 with children 0117 C8A, 0118 C8A, 0119 C8B, 0120 C8A, and $0121 \mathrm{C} 8 \mathrm{~B}$ suggests that at least individuals 0117 $\mathrm{C} 8 \mathrm{~A}, 0118 \mathrm{C} 8 \mathrm{~A}$, and $0120 \mathrm{C} 8 \mathrm{~A}$, as well as mother 
TABLE III

Observed and Expected ${ }^{*} C 8$ Types in Random Unrelated Individuals

\begin{tabular}{|c|c|c|c|c|c|c|c|c|}
\hline Population & No. & & AA & $A B$ & BB & AlA & AlB & AlAl \\
\hline Black & 164 & $\begin{array}{l}\text { (Obs.) } \\
\text { (Exp.) }\end{array}$ & $\begin{array}{l}74 \\
78.6\end{array}$ & $\begin{array}{l}63 \\
58.8\end{array}$ & $\begin{array}{l}11 \\
11.0\end{array}$ & $\begin{array}{l}16 \\
11.1\end{array}$ & $\begin{array}{l}0 \\
4.1\end{array}$ & $\begin{array}{l}0 \\
0.4\end{array}$ \\
\hline White & 165 & $\begin{array}{l}\text { (Obs.) } \\
\text { (Exp.) }\end{array}$ & $\begin{array}{l}74 \\
69.4\end{array}$ & $\begin{array}{l}65 \\
74.6\end{array}$ & $\begin{array}{l}25 \\
20.0\end{array}$ & $\begin{array}{l}1 \\
0.6\end{array}$ & $\begin{array}{l}0 \\
0.4\end{array}$ & $\begin{array}{l}0 \\
0.0\end{array}$ \\
\hline Oriental & 29 & $\begin{array}{l}\text { (Obs.) } \\
\text { (Exp.) }\end{array}$ & $\begin{array}{l}13 \\
12.4\end{array}$ & $\begin{array}{l}12 \\
13.1\end{array}$ & $\begin{array}{l}4 \\
3.5\end{array}$ & 0 & $\begin{array}{l}0 \\
-\end{array}$ & 0 \\
\hline
\end{tabular}

${ }^{*}$ Based on the Hardy-Weinberg equilibrium $(p+q)^{2}$ or $(p+q+r)^{2}$ where $p, q$, and $r$ represent observed gene frequencies.

1009 C8B must have inherited a C8 blank gene and are heterozygous C8-deficient though not so identified by functional or immunochemical study. The remaining mating of 1007 C8A with an untested husband 1008 and child $0114 \mathrm{C} 8 \mathrm{~A}$ is uninformative though consistent with the previous argument. In this kindred individuals who do not carry a $\mathrm{C}^{-}$gene have been previously misidentified as C8-deficient and individuals who do carry a $\mathrm{C}^{-}$gene as $\mathrm{C} 8$ normal. The erroneous conclusion of the linkage between C8d and HLA (35) is secondary to the failure to accurately identify heterozygotes by C8 antigenic and hemolytic assays.

In view of these observations, the difficulty in ascertainment of heterozygous C8-deficient individuals makes these two families less valuable in calculation of lod scores for linkage to other markers than initially thought, and they are therefore not included in the following analysis.

The analysis of C8 linkage represents lod scores for 18 autosomal markers (counting Rh or CDE as one trait). There were 24 families typed for $\mathrm{C} 8$ of which 19 were informative and contributed to the lod scores. In Table V,

TABLE IV

C8 Types of Mother-Cord Paired Serums

\begin{tabular}{|c|c|c|c|c|c|}
\hline \multicolumn{3}{|c|}{ Pair mother cord } & \multicolumn{3}{|c|}{ Pair mother cord } \\
\hline 1. & $\mathbf{A}$ & $\mathbf{A}$ & 14. & A & $\mathbf{A}$ \\
\hline 2. & A & $\mathbf{A}$ & 15. & A & $\mathbf{A}$ \\
\hline 3. & AB & $\mathrm{AB}$ & 16. & AB & AB \\
\hline 4. & $\mathbf{A B}$ & $\mathrm{AB}$ & 17. & $\mathbf{A B}$ & AB \\
\hline 5. & A & A & 18. & AB & $A^{*}$ \\
\hline 6. & B & $\mathrm{AB}^{*}$ & 19. & $\mathrm{AB}$ & $A^{*}$ \\
\hline 7. & A & A & 20. & $\mathrm{AB}$ & $\mathrm{AB}$ \\
\hline 8. & $\mathbf{A B}$ & $A^{*}$ & 21. & $\mathrm{AB}$ & $A^{*}$ \\
\hline 9. & $\mathbf{A}$ & $\mathbf{A}$ & 22. & $\mathrm{AB}$ & $\mathrm{AB}$ \\
\hline 10. & $\mathbf{A B}$ & $\mathrm{AB}$ & 23. & $\mathbf{A B}$ & AB \\
\hline 11. & $\mathrm{AB}$ & $\mathrm{AB}$ & 24. & $\mathrm{AB}$ & $\mathrm{AB}$ \\
\hline 12. & $\mathrm{AB}$ & $\mathrm{AB}$ & 25. & $\mathbf{A B}$ & $\mathrm{AB}$ \\
\hline 13. & A & A & 26. & A & A \\
\hline
\end{tabular}

* Pairs of different types. the total lod scores of $<-2.0$ are marked and statistically rule out linkage at the specified distance or closer. Since differences have been reported in the recombination rate in males and females for markers HLA-B and phosphoglucomutase 3 (44), the data were scored for HLA-B vs. C 8 by sex. Five families were informative for the male parent; five families were informative for the female parent; and seven for both. One family was not HLA typed. Table VI presents these scores. There is very little difference in the two sexes and no evidence that one sex shows linkage but the other does not.

Lod score analysis of the loci on chromosome 6 with known linkage relationships confirmed these linkages and achieved statistical significance for HLA-Bf and HLA-glyoxalase I. This indicates that chromosome 6 in these families did show the expected results for linked loci, strengthening the evidence that $\mathrm{C} 8$ is not closely linked to the HLA complex.

\section{DISCUSSION}

Genetic polymorphism in human C8 has been delineated and is in almost all ways analogous to previously described inherited structural variation in C3 $(1,2)$, C6 (3), and Bf (4). As is true of the other complement proteins, C8 in homozygotes exhibits charge heterogeneity. This heterogeneity probably reflects minor postsynthetic alterations in the molecule $(45,46)$. The inheritance pattern of $\mathrm{C} 8$ structural variants, as of almost all other complement gene products, is autosomal codominant.

The only unique feature of the genetic polymorphism in human C8 is the presence of a second zone of lysis cathodal to the primary informative area. It is conceivable that this secondary zone is related to the known propensity for C8 to associate with other terminal complement components (47). This zone, however, was found in C5-, C6-, and C7-deficient sera, making this possibility less likely. It has not been ruled out that this secondary zone represents C8-C9 complexes. There are remarkably few differences among the frequencies of the common $\mathrm{C} 8$ alleles in the major races 


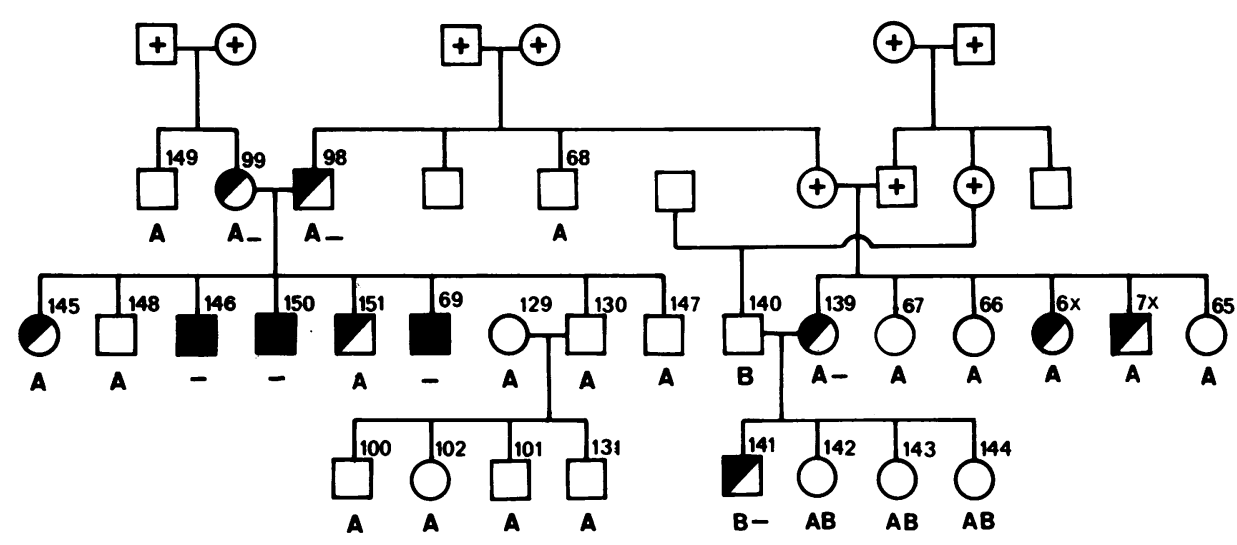

FIGURE 2 Family O-Q (13) with C8 deficiency. Homozygous C8-deficient individuals are completely blackened, whereas individuals now thought to be heterozygous C8-deficient are half-blackened. C8 allotypes are printed below each individual. Where a dash is given, genetic studies allow deduction of a null or silent allele.

of man. On the other hand, the less frequent allele $\mathrm{C}^{\mathrm{A} 1}$ appears to be more common in blacks than whites and was not detected in the relatively small number of orientals studied.

The identification of inherited homozygous deficiency of individual complement components has led to the study of the kindred of these individuals. A salient problem raised by these studies is whether the deficiency state is due to a dominant mutation reducing product activity (as in hereditary angioedema or hypoxanthine-guanine phosphoribosyltransferase deficiency) or due to a silent or null gene allelic at the structural locus.

The problem has been complicated in the case of the complement proteins by the difficulty encountered in identification of heterozygous deficient individuals. This is true for those who are obligate heterozygotes because they are parents or children of homozygous deficient individuals and for those who are encountered in population surveys without family studies. Also, some heterozygous deficient individuals occur in families in which no homozygous deficient individual is found. The failure to detect heterozygotes as well as the error of misidentification of normals as heterozygous deficient individuals has made linkage studies using the deficiency state difficult and often inaccurate. The certainty of identification of inherited heterozygous deficiency of individual complement components has in general varied inversely with the width of the normal range of these serum proteins. Although the parents and children of homozygous deficient individuals are obligate carriers of a deficiency gene, in matings not involving homozygous individuals detection has depended on low antigenic or functional levels of the protein in question. For C2 and C3, 50\% normal is <2 SD from the mean for both antigenic and functional assays. For other complement components, normal ranges are much broader.

Another method for detection of heterozygous deficient individuals has been to establish that a silent or null gene is allelic with a structural gene and then to demonstrate anomalous inheritance. To avoid tautological arguments, it is necessary $(a)$ to show inheritance of a single gene product in all obligate heterozygous deficient individuals and $(b)$ to demonstrate the inheritance in an offspring of a definite (preferably

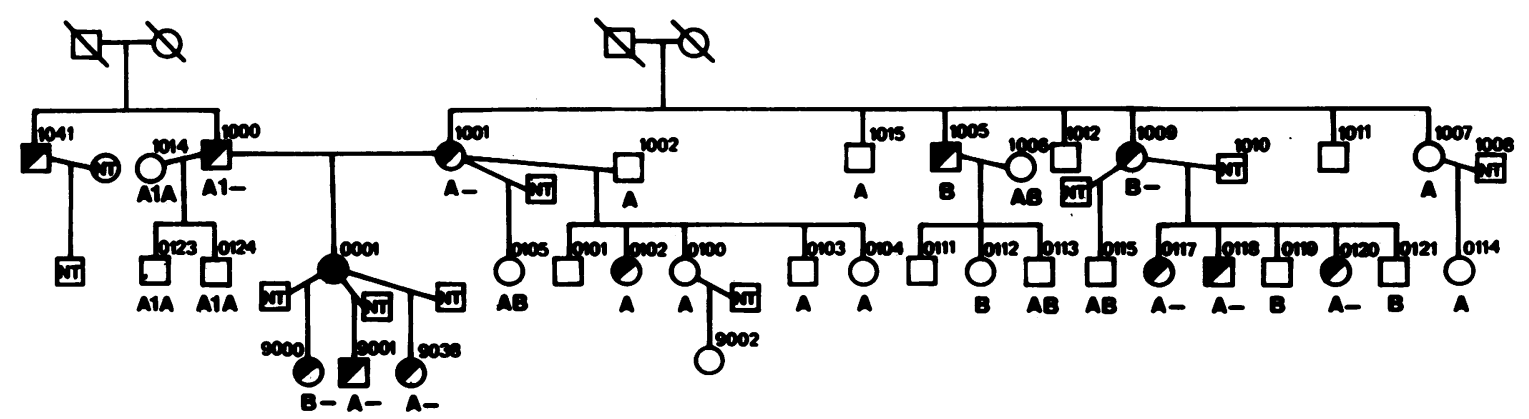

Figure 3 Family $16178(12,35)$ with C8 deficiency. Deficiency and allotypes the same as Fig. 1. 
TABLE V

Lod Scores for Linkage of C8 with 18 Autosomal Markers*

\begin{tabular}{|c|c|c|c|c|c|c|}
\hline Trait & $\theta=0.01$ & $\theta=0.05$ & $\theta=0.1$ & $\theta=0.2$ & $\theta=0.3$ & $\theta=0.4$ \\
\hline \multicolumn{7}{|c|}{ Chromosome 6} \\
\hline $\mathrm{C} 2$ & $-2.5839 \ddagger$ & -1.2417 & -0.7145 & -0.2756 & -0.0963 & -0.0209 \\
\hline GLOI & $-14.4477 \hbar$ & $-7.0411 \ddagger$ & $-4.1032 \ddagger$ & -1.6028 & -0.5513 & -0.1134 \\
\hline Bf & -3.2858 & -0.7738 & 0.0639 & 0.5002 & 0.4080 & 0.1495 \\
\hline $\mathbf{P}$ & $-4.0727 \ddagger$ & -1.5359 & -0.6629 & -0.1109 & 0.0076 & 0.0112 \\
\hline \multicolumn{7}{|c|}{ Chromosome 1} \\
\hline Duffy & $-8.6537 \ddagger$ & $-4.0076 \rrbracket$ & $-2.2184 \rrbracket$ & -0.7759 & -0.2328 & -0.0413 \\
\hline Rh-C & $-8.4887 \ddagger$ & $-3.9123 \ddagger$ & $-2.1945 \ddagger$ & -0.8331 & -0.2931 & -0.0639 \\
\hline Rh-D & -0.7619 & -0.1307 & 0.0754 & 0.1624 & 0.1129 & 0.0360 \\
\hline Rh-E & $-3.3135 \ddagger$ & -1.3432 & -0.0658 & -0.0614 & 0.0704 & 0.0411 \\
\hline \multicolumn{7}{|c|}{ Chromosome 7} \\
\hline $\mathbf{J k}$ & $-2.1707 \ddagger$ & -0.8950 & -0.4408 & -0.1189 & -0.0242 & -0.0022 \\
\hline \multicolumn{7}{|c|}{ Chromosome 9} \\
\hline $\mathrm{ABO}$ & $-6.5300 \ddagger$ & $-3.1152 \ddagger$ & -1.7446 & -0.5964 & -0.1588 & -0.0203 \\
\hline \multicolumn{7}{|c|}{ Chromosome 16} \\
\hline $\mathrm{Hp}$ & $-7.0115 \ddagger$ & $-3.6062 \ddagger$ & -2.2185 & -0.9691 & -0.3786 & -0.0886 \\
\hline \multicolumn{7}{|c|}{ Unassigned } \\
\hline $\mathbf{K}$ & 0.5893 & 0.5355 & 0.4656 & 0.3182 & 0.1703 & 0.0492 \\
\hline Le & $-4.0597 \ddagger$ & $-2.0075 \ddagger$ & -1.1800 & -0.4702 & -0.1683 & -0.0368 \\
\hline $\mathrm{Lu}$ & 0.0002 & 0.0002 & 0.0002 & 0.0001 & 0.0000 & 0.000 \\
\hline MNSs & $-9.5188 \ddagger$ & $-3.7579 \ddagger$ & -1.7096 & -0.2989 & +0.0484 & +0.0461 \\
\hline
\end{tabular}

* Assuming no difference in recombination frequencies in males and females.

$\ddagger P<0.01$; reject linkage at that value of recombination, or closer.

obligate) heterozygous deficient individual of an apparent homozygous phenotype different from the phenotype of the heterozygous deficient parent. Identification of possible heterozygous deficient individuals can then be made by showing similar anomalous inheritance in other matings.

On the basis of studies of serum C8 concentrations of families with homozygous deficient individuals, linkage between C8 and other loci was sought with conflicting results $(13,14,35)$. In the present study we demonstrate the inheritance of only a single C8

TABLE VI

Scores for HLA-B vs. C8 by Sex*

\begin{tabular}{lrrrrrr}
\hline & $\theta=0.01$ & $\theta=0.05$ & $\theta=0.1$ & $\theta=0.2$ & $\theta=0.3$ & $\theta=0.4$ \\
\hline Male & -7.33 & -3.54 & -2.02 & -0.76 & -0.26 & -0.05 \\
Female & -1.63 & -0.38 & 0.0 & 0.20 & 0.13 & 0.05 \\
\hline
\end{tabular}

$* \theta=$ recombination frequency. allotype by obligate heterozygous C8-deficient individuals. No mating of an obligate heterozygous deficient individual is informative for absolute establishment of $\mathrm{C}^{-}$as allelic at the C8 structural locus. However, in both families studied for deficiency, a mating of a sibling of an obligate heterozygous deficient individual demonstrates anomalous inheritance in an offspring from which we have concluded that $\mathrm{C}^{-}$is allelic at the $\mathrm{C} 8$ structural locus. The argument has been strengthened by examining these two families individually and arguing that $\mathrm{C}^{-}$is allelic from examination of the mating of a suspected and previously identified heterozygous deficient individual in family $O-Q$ and then demonstration of a similar anomalously inherited C8 allotype in a mating in family 16178 and deduction that these individuals must be heterozygous deficient though not so identified by functional or immunochemical assay. No other single or simple explanation fits these data. An alternative hypothesis is that $\mathrm{C}^{-}$ is a dominant mutation causing suppression of $\mathrm{C} 8$ levels. 
In this case for individuals $0123 \mathrm{C} 8 \mathrm{AlA}$ and $0124 \mathrm{C} 8 \mathrm{AlA}$ to have inherited a $\mathrm{C}^{-}$gene would require this gene to have effect on both C8 structural loci such that $\cong 50 \%$ of the normal level were synthesized and would require a separate explanation for the phenotypes of individuals 0177, 0118, and 0120 C8A with a parent 1009 whose $\mathrm{C} 8$ phenotype is $\mathrm{B}$. It is concluded that in these families $\mathrm{C}^{-}$is allelic with the $\mathrm{C} 8$ structural locus.

In a previous paper (31) C8 was thought to show linkage to Duffy, but the current studies rule out close linkage of these loci. Although $\mathrm{C} 2$ and $\mathrm{Bf}$ are intimately associated on chromosome $6(8)$, evidence now exists to rule out close linkage of HLA-B to C3 (28) and C6 (32). The present data rule out close linkage of $\mathrm{C} 8$ to HLA, C2, Bf, C3, and C6.

\section{ACKNOWLEDGMENTS}

We wish to thank Doctors Vera and Isidio Calich, Instituto de Ciências Biomédicas, Universidade de São Paulo, São Paulo, Brasil, for providing some of the samples in this study, and Debbie Marcus for technical assistance.

This work was supported by grants AI 14157, AI 13626, AM 16392, AI 15033, MCH 927, HD 04612, HD 05615 HD 00345, and CA 18488 from the National Institutes of Health, grant 6-183 from The National Foundation-March of Dimes, and The Charles E. Merrill Trust. Computing assistance was obtained from the Health Sciences Computing Facility, University of California at Los Angeles, NIH special research grant RR-3.

\section{REFERENCES}

1. Alper, C. A., and R. P. Propp. 1968. Genetic polymorphism of the third component of human complement $\left(C^{\prime} 3\right)$. J. Clin. Invest. 47: 2181-2191.

2. Azen, E. A., and O. Smithies. 1968. Genetic polymorphism of $C^{\prime} 3\left(\beta_{1 \mathrm{c}}\right.$-globulin) in human serum. Science (Wash. D. C.). 162: 905-907.

3. Hobart, M. J., P. J. Lachmann, and C. A. Alper. 1975. Polymorphism of human C6. In Protides of the Biological Fluids. H. Peeters, editor. Pergamon Press, Inc., Elmsford, New York. 575-580.

4. Alper, C. A., T. Boenisch, and L. Watson. 1972. Genetic polymorphism in human glycine-rich beta-glycoprotein. J. Exp. Med. 135: 68-80.

5. Teisberg, P., B. Olaisen, R. Jonassen, T. Gedde-Dahl, Jr., and $\mathrm{E}$. Thorsby. 1977. The genetic polymorphism of the fourth component of human complement: methodological aspects and a presentation of linkage and association data relevant to its localization in the HLA region. J. Exp. Med. 146: $1380-1389$.

6. Mauff, G. 1977. Habilitationsschrift: Untersuchungen zum Komplementssystem des Menschen. Genetik und Biochemie der dritten und Vierten Komponente des Komplementssystems sowie des Properdinfaktor B. Universität Köln, Cologne, West Germany. 151-160.

7. O'Neill, G. J., S. Y. Yang, and B. Dupont. 1978. Two HLAlinked loci controlling the fourth component of human complement. Proc. Natl. Acad. Sci. U. S. A. 75: 51655169.

8. Alper, C. A. 1976. Inherited structural polymorphism in human C2: evidence for genetic linkage between $C 2$ and Bf. J. Exp. Med. 144: 1111-1115.
9. Hobart, M. J., and P. J. Lachmann. 1976. Allotypes of complement components in man. Transplant. Rev. 32: $26-42$.

10. Hobart, M. J., V. Joysey, and P. J. Lachmann. 1978. Inherited structural variation and linkage relationships of C7. J. Immunogenet. 5: 157-163.

11. Alper, C. A., and F. S. Rosen. 1976. Genetics of the complement system. Adv. Hum. Genet. 7: 141-188.

12. Petersen, B. H., J. A. Graham, and G. F. Brooks. 1976. Human deficiency of the eighth component of complement. The requirement of C8 for serum Neisseria gonorrhoeae bactericidal activity. J. Clin. Invest. 57: 283-290.

13. Giraldo, G., L. DeGos, E. Beth, M. Sasportes, A. Marcelli, R. Gharbi, and N. K. Day. 1977. C8 deficiency in a family with Xeroderma Pigmentosum. Lack of linkage to the HLA region. Clin. Immunol. Immunopathol. 8: 377-384.

14. Jasin, H. E. 1977. Absence of the eighth component of complement in association with systemic lupus erythematosus-like disease. J. Clin. Invest. 60: 709-715.

15. Allen, F. H., Jr. 1974. Linkage of HL-A and GBG. Vox Sang. 27: $382-384$.

16. Alper, C. A., R. P. Propp, M. R. Klemperer, and F. S. Rosen. 1969. Inherited deficiency of the third component of complement $\left(\mathrm{C}^{\prime} 3\right)$. J. Clin. Invest. 48: 553-557.

17. Fu, S. M., H. G. Kunkel, H. P. Brusman, F. H. Allen, Jr., and M. Fotino. 1974. Evidence for linkage between HL-A histocompatibility genes and those involved in the synthesis of the second component of complement. J. Exp. Med. 140: 1108-1111.

18. Day, N. K., P. L'Esperance, R. A. Good, A. F. Michael, J. A. Hansen, B. Dupont, and C. Jersild. 1975. Hereditary C2 deficiency: genetic studies and association with the HL-A system. J. Exp. Med. 141: 1464-1469.

19. Meo, T., J. Atkinson, M. Bernoco, D. Bernoco, and R. Ceppelini. 1976. Mapping of the HLA locus controlling C2 structural variants and linkage disequilibrium between alleles C2 ${ }^{2}$ and Bw15. Eur. J. Immunol. 6: 916-919.

20. Pariser, K. M., D. Raum, E. M. Berkman, C. A. Alper, and V. Agnello. 1978. Evidence for a silent or null gene in hereditary C2 deficiency. J. Immunol. 121: 2580-2581.

21. Gibson, D. J., D. Glass, C. B. Carpenter, and P. H. Schur. 1976. Hereditary C2 deficiency: diagnosis and HLA gene complex associations. J. Immunol. 116: 1065-1070.

22. Glass, D., D. Raum, D. Balavitch, E. Kagan, A. Rabson, P. H. Schur, and C. A. Alper. 1978. Inherited deficiency of the sixth component of complement: a silent or null gene. J. Immunol. 120: 538-541.

23. Raum, D., D. Glass, C. B. Carpenter, C. A. Alper, and P. H. Schur. 1976. The chromosomal order of genes controlling the major histocompatibility complex, properdin factor $\mathbf{B}$, and deficiency of the second component of complement. J. Clin. Invest. 58: 1240-1248.

24. Raum, D., D. Glass, C. B. Carpenter, P. H. Schur, and C. A. Alper. 1979. Mapping of the structural gene for the second component of complement with respect to the human histocompatibility complex. Am. J. Hum. Genet. 31: 35-41.

25. Lachmann, P. J., and M. J. Hobart. 1978. C6-C7: a further "complement supergene". Clin. Exp. Immunol. 33: 193198.

26. Rittner, C., G. Hauptmann, H. Grosse-Wilde, E. Grosshans, M. M. Tongio, and S. Mayer. 1975. Linkage between HLA (major histocompatibility complex) and genes controlling the synthesis of the fourth component of complement. In Histocompatibility Testing, 1975 F. KissmeyerNielsen, editor. Munksgaard, Copenhagen. 945-954.

27. Ochs, H. D., S. I. Rosenfeld, E. D. Thomas, E. R. Giblett, C. A. Alper, B. Dupont, J. G. Schaller, B. C. Gilliland, J. A. 
Hansen, and R. J. Wedgwood. 1976. Linkage between the gene (or genes) controlling synthesis of the fourth component of complement and the major histocompatibility complex. N. Engl. J. Med. 296: 470-475.

28. Gedde-Dahl, T., Jr., P. Teisberg, and E. Thorsby. 1974. C3 polymorphism: genetic linkage relations. Clin. Genet. 6: $66-72$.

29. Rosenfeld, S. I., M. E. Kelly, and J. P. Leddy. 1976. Hereditary deficiency of the fifth component of complement in man. I. Clinical, immunochemical, and family studies. J. Clin. Invest. 57: 1626-1634.

30. Rosenfeld, S. I., J. Baum, R. T. Steigbigel, and J. P. Leddy. 1976. Hereditary deficiency of the fifth component of complement in man. II. Biological properties of C5-deficient human serum. J. Clin. Invest. 57: 1635-1643.

31. Leddy, J. P., M. M. Frank, T. Gaither, J. Baum, and M. R. Klemperer. 1974. Hereditary deficiency of the sixth component of complement in man. I. Immunochemical, biologic, and family studies. J. Clin. Invest. 53: 544-553.

32. Hobart, M. J., P. J. L. Cook, and P. J. Lachmann. 1977. Linkage studies with C6. J. Immunogenet. 4: 423-428.

33. Rittner, C. H., W. Opferkuch, B. Wellek, H. Grosse-Wilde, and P. Wernet. 1976. Lack of linkage between genes controlling the synthesis of the seventh component of complement and the HLA region on chromosome No. 6 in man. Hum. Genet. 34: 137-142.

34. Dêlage, J. M., P. Bergeron, J. Simar, G. Lehner-Netsch, and E. Prochazka. 1977. Hereditary C7 deficiency. Diagnosis and HLA studies in a French-Canadian family. J. Clin. Invest. 60: 1061-1069.

35. Merritt, A. D., B. H. Petersen, A. A. Biegel, D. A. Meyers, G. F. Brooks, and M. E. Hodes. 1976. Chromosome 6: linkage of the eighth component of complement (C8) to the histocompatibility region (HLA). Cytogenet. Cell Genet. 16: 331-334.

36. Alper, C. A., H. R. Colten, F. S. Rosen, A. R. Rabson, G. M. Macnab, and J. S. S. Gear. 1972. Homozygous deficiency of C3 in a patient with repeated infections. Lancet. II: 1179-1181.

37. Davis, A. E., III, J. S. Davis, IV, A. R. Rabson, S. G. Osofsky, H. R. Colten, F. S. Rosen, and C. A. Alper. 1977.
Homozygous C3 deficiency: detection of C3 by radioimmunoassay. Clin. Immunol. Immunopathol. 8: 543550.

38. Schur, P. H. 1975. Complement in lupus. In Clinics in Rheumatic Diseases, Systemic Lupus Erythematosus. N. S. Rothfield, editor. W. B. Saunders Company, Philadelphia. 1: 519-543.

39. Glass, D., D. Raum, D. Gibson, J. S. Stillman, and P. H. Schur. 1976. Inherited deficiency of the second component of complement. J. Clin. Invest. 58: 853-861.

40. Glass, D., N. A. Soter, D. Gibson, C. B. Carpenter, and P. H. Schur. 1976. An association between HLA and cutaneous necrotizing venulitis. Arthritis Rheum. 19: 945-949.

41. Ott, J. 1974. Estimation of the recombination fraction in human pedigrees: efficient computation of the likelihood for human linkage studies. Am. J. Hum. Genet. 26: 588597.

42. Mittal, K. K., M. R. Mickey, D. P. Singal, and P. I. Terasaki. 1968. Serotyping for homotransplantation. XVIII. Refinement of microdroplet lymphocyte cytotoxicity test. Transplantation (Baltimore). 6: 913-927.

43. Awdeh, Z. L., A. R. Williamson, and B. A. Askonas. 1968. Isoelectric focusing in polyacrylamide gel and its application to immunoglobulins. Nature (Lond.). 219: 66-67.

44. Lamm, L. R., I-L. Thorsen, G. B. Petersen, J. Jorgensen, K. Henningsen, B. Bech, and F. Kissmeyer-Nielsen. 1975. Data on the HL-A linkage group. Ann. Hum. Genet. 38: 383-390.

45. Edmundson, A. B., and C. H. W. Hirs. On the structure of whale myoglobulin. I. The amino acid composition and terminal groups of the chromatographically purified protein. J. Mol. Biol. 5: 663-682.

46. Awdeh, Z. L., A. R. Williamson, and B. A. Askonas. 1970. One cell-one immunoglobulin. Origin of limited heterogeneity of myeloma proteins. Biochem. J. 116: 241-248.

47. Kolb, W. P., J. A. Haxby, C. M. Arroyave, and H. J. MüllerEberhard. 1972. Molecular analysis of the membrane attack mechanism of complement. J. Exp. Med. 135: 549566 . 